\title{
ANAEROBIC METABOLISM DURING ACTIVITY IN AMPHIBIANS
}

\author{
ALBERT F. BENNE'T'T and PAUL LICH'T \\ Department of Zoology, University of California, Berkeley, California 94720, U.S.A.
}

(Received 26 June 1973)

\begin{abstract}
Total lactate production (anaerobic energetic generation) during maximal activity was measured in eight species of amphibians.

2. Slow-moving animals, exemplified by Bufo boreas, produce small amounts of lactate and do not exhaust. In contrast, fast-moving, saltatory forms, such as Rana pipiens and Batrachoseps attenuatus, have high levels of lactate generation and are unable to sustain maximal activity.

3. Aquatic species rely on air gulping during activity and show little anaerobiosis.

4. The temperature dependence of anaerobic energy generation is high $\left(Q_{10}=1 \cdot 5-3 \cdot 9\right)$ for all species.

5. Levels of amphibian lactate production are lower than those of lizards and show greater interspecific variation.

6. The rate of lactate production is directly correlated with predator avoidance. Noxious-tasting or aggressive amphibians have low anaerobic scopes; others rely on anaerobiosis for energy for rapid flight. Rapid activity in amphibians appears possible only at the expense of extensive anaerobiosis.
\end{abstract}

\section{INTRODUCTION}

RECENT measurements of anaerobic metabolism in lizards demonstrated that lactate generation has a considerable influence on energy production and stamina for activity in these reptiles (Bennett \& Licht, 1972; Bennett \& Dawson, 1972). Over 90 per cent of the energetic (A'TP) production during a burst of activity is anaerobically derived, and lizards are characterized by rapid exhaustibility. Furthermore, lizards showed little thermal dependence in the rates of lactate production and there was remarkably little interspecific variation in anaerobiosis.

The physiology of activity in amphibia has received much less study than that of most other vertebrate groups: the first investigations of oxygen consumption during activity have been made only recently (Bennett \& Licht, 1973; Seymour, 1973). Several factors suggest that amphibians might depend upon anaerobiosis even more than do reptiles. Amphibians have less well-developed respiratory systems and rely extensively on cutaneous respiration. Some, such as the plethodontid salamanders, are lungless and rely almost completely on their integument to supply oxygen (Elkan, 1955; Czopek, 1962a; Whitford \& Hutchison, 1965). 
Further, amphibians are active at low body temperatures (see Brattstrom, 1963), and the dependence on anaerobic metabolism was found to increase with decreasing body temperature in several species of lizards (Bennett \& Dawson, 1972; Bennett $\&$ Licht, 1972). To investigate the patterns of anaerobiosis in amphibians, lactate production was measured during maximal enforced activity at different temperatures. An ecologically and phylogenetically diverse assemblage of urodeles and anurans was examined.

\section{MATERIALS AND METHODS}

Amphibians of the following species were collected locally in Northern California: Aneides flavipunctatus (mean weight, $1.89 \mathrm{~g}$ ), A. lugubris (4.09 g), Batrachoseps attenuatus $(0 \cdot 71 \mathrm{~g})$, Bufo boreas halophilus $(22 \cdot 0 \mathrm{~g})$, Hyla regilla $(2 \cdot 61 \mathrm{~g})$ and Rana catesbeiana tadpoles $(9.19 \mathrm{~g})$. Notophthalmus viridescens $(1.51 \mathrm{~g})$ and Rana pipiens adults $(39.7 \mathrm{~g})$ were obtained from commercial suppliers. Animals were maintained in the laboratory at $15-20^{\circ} \mathrm{C}$ for over a week and fasted for at least 3 days before experimentation.

The formation of lactic acid was measured as an index of anaerobic metabolism. The method employed was identical to that used previously for lizards (Bennett $\&$ Licht, 1972). Briefly, animals were killed by concussion and homogenized in cold perchloric acid. Total lactate in these whole-body homogenates was then determined enzymatically. Animals were weighed and placed in individual covered containers containing wet filter paper or water (for the aquatic Notophthalmus and larval $R$. catesbeiana). These containers were placed in the dark overnight in a controlled-temperature cabinet set at $10,15,20$ or $30^{\circ} \mathrm{C}$. After the animals had remained undisturbed for at least $18 \mathrm{hr}$, individuals were removed and stimulated to maximal activity for $30 \mathrm{sec}$ to determine anaerobic scope (the maximal rate of lactate formation) and others were stimulated for $10 \mathrm{~min}$ (or until exhaustion) to determine anaerobic capacity (total lactate produced). Stimulation consisted of prodding or pinching the animals with blunt-nosed forceps to keep them in constant motion (running, hopping or swimming). Such stimulation was highly effective in eliciting activity comparable to that obtained by electrical stimulation (Bennett \& Licht, 1973). All species had free access to normal levels of environmental oxygen during stimulation. In addition, one group of Notophthalmus was prevented from surfacing during activity by confinement in a submerged fine-mesh wire screen cage. Post-active and resting control animals were immediately analyzed for total lactate content. The amount of lactate formed during activity was calculated from the difference between control and stimulated animals and expressed as mg lactate/g body wt.

\section{RESULTS}

Lactate levels in amphibians before and after activity are reported in Tables 1 and 2. There was considerable interspecific diversity in both the behavioral response to stimulation and in the associated lactate production. The anaerobic scopes-maximum rates of lactate formation-may be calculated from the lactate production during the first $30 \mathrm{sec}$ of stimulation, when the animals were most responsive. These scopes showed a generally high thermal dependence: $Q_{10}$ values for Bufo were $1.53-1.64$ at $10-30^{\circ} \mathrm{C}$; for $R$. pipiens, $1.50-1.84$ at $10-20^{\circ} \mathrm{C}$ and 0.92 for $20-30^{\circ} \mathrm{C}$; for Hyla, 3.86 at $10-20^{\circ} \mathrm{C}$; and for Batrachoseps, 2.02 at $10-20^{\circ} \mathrm{C}$. Differences in the magnitude of the anaerobic scope among species at each temperature range up to tenfold (Fig. 1). 
TABle 1-Lactate CONTENT OF terRestrial amphibians AT REST AND DURING MaXimal ENFORCED ACTIVITY

Lactate content

\begin{tabular}{|c|c|c|c|c|c|c|}
\hline Species & $\begin{array}{c}T_{\mathrm{b}} \\
\left({ }^{\circ} \mathrm{C}\right)\end{array}$ & Rest & $\begin{array}{l}30 \mathrm{sec} \\
\text { active }\end{array}$ & $\begin{array}{l}\text { Level of } \\
\text { activity }\end{array}$ & $\begin{array}{l}10 \min \\
\text { active }\end{array}$ & $\begin{array}{c}\text { Level of } \\
\text { final activity }\end{array}$ \\
\hline $\begin{array}{l}\text { Aneides } \\
\quad \text { flavipunctatus }\end{array}$ & 20 & $\begin{array}{c}8 \cdot 3 \pm 1 \cdot 2 \\
(3)\end{array}$ & $\begin{array}{c}35 \cdot 6 \pm 3 \cdot 5 \\
(4)\end{array}$ & Fast run & $\begin{array}{c}117 \cdot 7 \pm 2 \cdot 5 \\
(5)\end{array}$ & Slow walk \\
\hline $\begin{array}{l}\text { Aneides } \\
\quad \text { lugubris }\end{array}$ & 20 & $\begin{array}{c}20 \cdot 1 \pm 3 \cdot 6 \\
(3)\end{array}$ & $\begin{array}{c}40 \cdot 8 \pm 3 \cdot 7 \\
(4)\end{array}$ & Fast run & $\begin{array}{l}84 \cdot 1 \pm 8 \cdot 2 \\
\quad(5)\end{array}$ & $\begin{array}{l}\text { Slow, walk; } \\
\text { threatening }\end{array}$ \\
\hline \multirow[t]{2}{*}{$\begin{array}{l}\text { Batrachoseps } \\
\text { attenuatus }\end{array}$} & 10 & $\begin{array}{c}19 \cdot 0 \pm 0 \cdot 5 \\
(3)\end{array}$ & $\begin{array}{c}51 \cdot 2 \pm 4 \cdot 4 \\
(5)\end{array}$ & \multirow{2}{*}{\multicolumn{2}{|c|}{$\begin{array}{c}\text { Very rapid } 115 \cdot 5 \pm 2 \cdot 6 \\
\text { jumping }(5) \\
165 \cdot 5 \pm 2 \cdot 7 \\
(5)\end{array}$}} & Slow walk \\
\hline & 20 & $\begin{array}{c}20 \cdot 3 \pm 0.7 \\
(3)\end{array}$ & $\begin{array}{c}85 \cdot 5 \pm 4 \cdot 9 \\
(4)\end{array}$ & & & \\
\hline \multirow[t]{3}{*}{ Bufo boreas } & 10 & $\frac{13 \cdot 3 \pm 1 \cdot 1}{(3)}$ & $\begin{array}{c}27 \cdot 6 \pm 2 \cdot 2 * \\
(5)\end{array}$ & \multirow[t]{3}{*}{$\begin{array}{l}\text { Moderate } \\
\text { walk }\end{array}$} & $\begin{array}{c}57 \cdot 8 \pm 3 \cdot 4 \\
(5)\end{array}$ & \multirow[t]{3}{*}{$\begin{array}{l}\text { Moderate } \\
\text { walk }\end{array}$} \\
\hline & 20 & $\begin{array}{c}10 \cdot 7 \pm 2 \cdot 4 \\
(4)\end{array}$ & $\begin{array}{c}34 \cdot 2 \pm 1 \cdot 9 * \\
(5)\end{array}$ & & $\begin{array}{l}65 \cdot 5 \pm 3 \cdot 8 \\
(5)\end{array}$ & \\
\hline & 30 & $\begin{array}{c}16 \cdot 1 \pm 0 \cdot 6 \\
(3)\end{array}$ & $52 \cdot 1 \pm 2 \cdot 1 *$ & & $\begin{array}{c}81 \cdot 7 \pm 6 \cdot 1 \\
(4)\end{array}$ & \\
\hline \multirow[t]{2}{*}{ Hyla regilla } & 10 & $\begin{array}{c}26 \cdot 6 \pm 2 \cdot 4 \\
(3)\end{array}$ & $\begin{array}{l}36 \cdot 9 \pm 1 \cdot 4 \\
\quad(5)\end{array}$ & $\begin{array}{l}\text { Rapid } \\
\text { jumping }\end{array}$ & $\begin{array}{c}94 \cdot 6 \pm 9 \cdot 2 \\
(4)\end{array}$ & \multirow[t]{2}{*}{$\begin{array}{l}\text { Slow, } \\
\text { unco- } \\
\text { ordinated } \\
\text { jumps }\end{array}$} \\
\hline & 20 & $\begin{array}{c}28 \cdot 2 \pm 1 \cdot 2 \\
(3)\end{array}$ & $\begin{array}{c}68 \cdot 0 \pm 2 \cdot 3 \\
(4)\end{array}$ & & $\begin{array}{c}126 \cdot 6 \pm 2 \cdot 7 \\
(5)\end{array}$ & \\
\hline \multirow[t]{4}{*}{ Rana pipiens } & 10 & $\begin{array}{c}9 \cdot 3 \pm 0 \cdot 7 \\
(3)\end{array}$ & $\begin{array}{c}27 \cdot 5 \pm 0 \cdot 9 \\
\quad(6)\end{array}$ & $\begin{array}{r}\text { Very rapid } \\
\text { jumping }\end{array}$ & $\begin{array}{c}78 \cdot 7 \pm 3 \cdot 7 \dagger \\
(5)\end{array}$ & \multirow[t]{4}{*}{ Exhausted } \\
\hline & 15 & $\begin{array}{c}13 \cdot 5 \pm 0 \cdot 5 \\
(3)\end{array}$ & $\begin{array}{c}40 \cdot 8 \pm 2 \cdot 7 \\
(5)\end{array}$ & & $\begin{array}{c}119 \cdot 8 \pm 5 \cdot 4 \dagger \\
(4)\end{array}$ & \\
\hline & 20 & $\begin{array}{c}14 \cdot 8 \pm 1 \cdot 7 \\
(3)\end{array}$ & $\begin{array}{c}65 \cdot 5 \pm 1 \cdot 9 \\
(5)\end{array}$ & & $\begin{array}{c}128 \cdot 6 \pm 7 \cdot 2 \dagger \\
(4)\end{array}$ & \\
\hline & 30 & $\begin{array}{c}28 \cdot 9 \pm 3 \cdot 7 \\
\text { (3) }\end{array}$ & $\begin{array}{c}73 \cdot 4 \pm 7 \cdot 5 \\
(5)\end{array}$ & & $\begin{array}{c}143 \cdot 4 \pm 8 \cdot 6 \dagger \\
\text { (5) }\end{array}$ & \\
\hline
\end{tabular}

* 1 min activity +5 min activity.

The mean value lactate content is reported in mg lactate/g body wt. \pm S.E. of mean; the number of animals is given in parentheses.

Anaerobic capacity was previously defined as total lactate produced during activity to exhaustion (Bennett \& Licht, 1972). All of the amphibia, except $R$. pipiens, were able to sustain some degree of activity throughout the $10-\mathrm{min}$ stimulation. However, in all cases the rates of lactate production were very low after the first $2 \mathrm{~min}$ (Fig. 2) and presumably were approaching an anaerobic asymptote. Hence, anaerobic capacities were estimated from the lactate levels at $10 \mathrm{~min}$. These estimates are presented in Fig. 3. The pattern of response is similar to that seen for anaerobic scope: species that form a small amount of lactate during initial activity do not attain high concentrations of lactate with continued activity. 
Table 2-Lactate CONTENT OF aquatic amphibians at Rest and DURING Maximal ACTIVITY AT $20^{\circ} \mathrm{C}$

\begin{tabular}{|c|c|c|c|}
\hline Species & Condition & Lactate control & Level of activity \\
\hline \multirow[t]{6}{*}{$\begin{array}{l}\text { Nothophthalmus } \\
\text { viridescens }\end{array}$} & Resting in water & $\begin{array}{c}53 \cdot 4 \pm 4 \cdot 6 \\
(3)\end{array}$ & Rest \\
\hline & $\begin{array}{l}30 \text { sec active- }- \text { swimming } \\
\text { in water }\end{array}$ & $59 \cdot 8 \pm 8 \cdot 0$ & Rapid swimming \\
\hline & $\begin{array}{l}10 \text { min active-swimming } \\
\text { in water with access } \\
\text { to air }\end{array}$ & $\begin{array}{l}65 \cdot 7 \pm 6 \cdot 4 \\
\quad(5)\end{array}$ & Rapid swimming \\
\hline & $\begin{array}{l}10 \text { min active-swimming } \\
\text { in water without access } \\
\text { to air }\end{array}$ & $\begin{array}{c}110 \cdot 8 \pm 8 \cdot 6 \\
(3)\end{array}$ & $\begin{array}{l}\text { Greatly reduced activity; } \\
\text { loss of orientation and } \\
\text { coordination }\end{array}$ \\
\hline & $\begin{array}{l}30 \text { sec active-walking } \\
\text { on land }\end{array}$ & $\begin{array}{l}68 \cdot 9 \pm 8 \cdot 2 \\
\quad(3)\end{array}$ & Moderate walking \\
\hline & $\begin{array}{l}10 \text { min active-walking } \\
\text { on land }\end{array}$ & $\begin{array}{l}82 \cdot 8 \pm 2 \cdot 1 \\
\quad(3)\end{array}$ & Slow walking \\
\hline \multirow[t]{3}{*}{$\begin{array}{l}\text { Rana } \\
\quad \text { catesbeiana }\end{array}$} & Resting in water & $\begin{array}{c}18 \cdot 0 \pm 0 \cdot 3 \\
(3)\end{array}$ & Rest \\
\hline & $\begin{array}{l}30 \text { sec active-swimming } \\
\text { in water }\end{array}$ & $\begin{array}{c}24 \cdot 0 \pm 0 \cdot 8 \\
(5)\end{array}$ & Rapid swimming \\
\hline & $\begin{array}{l}10 \text { min active swimming } \\
\text { in water }\end{array}$ & $\begin{array}{c}66 \cdot 7 \pm 4 \cdot 6 \\
(5)\end{array}$ & $\begin{array}{l}\text { Slow, lethargic } \\
\text { swimming }\end{array}$ \\
\hline
\end{tabular}

The mean value of lactate content is reported in mg lactate/g body wt. \pm S.E. of mean; the number of animals is reported in parentheses.

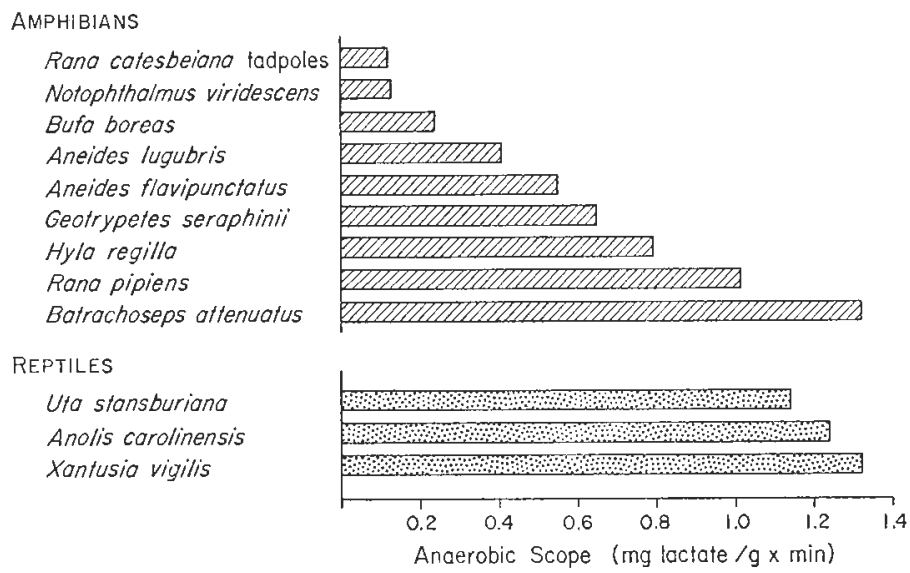

Fig. 1. Anaerobic scope in amphibians and lizards at $20^{\circ} \mathrm{C}$. Saurian data are taken from Bennett \& Licht (1972); data for the caecilian, G. seraphinii, are from 


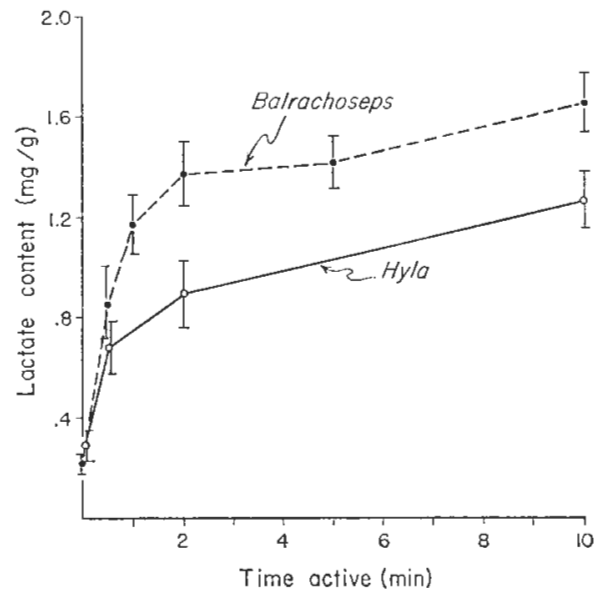

FIG. 2. Lactate content of $B$. attenuatus and $H$. regilla during activity at $20^{\circ} \mathrm{C}$. Mean values and $95 \%$ confidence limits of the means are reported by circles and vertical lines, respectively.

AmPHIBIANs
Nolophlhalmus viridescens
Rana catesbeiana tadpales
Bufo boreas
Aneides lugubris
Geatrypetes seraphinit
Hyla regilla
Aneides flavipuntatus
Rana pipiens
Batrachoseps attenuatus

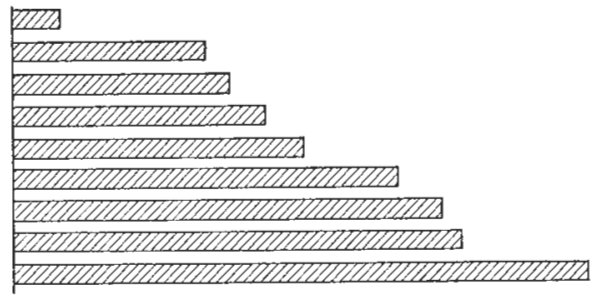
REPTILES
Lygosoma laterale Anolis carolinensis Uta stansburiana Xantusio vigilis

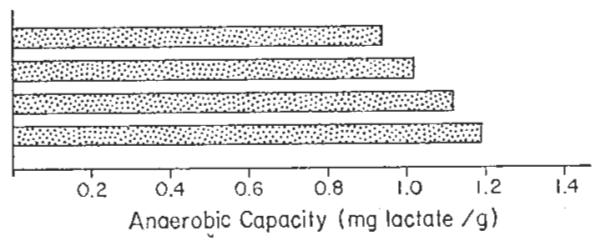

FIG. 3. Anaerobic capacity in amphibians and lizards at $20^{\circ} \mathrm{C}$. Capacity for all amphibians except $R$. pipiens is estimated from lactate content after $10 \mathrm{~min}$ of activity. Saurian data are from Bennett \& Licht (1972); data for the caecilian, G. seraphinii, are from Bennett \& Wake (1974).

These differences in anaerobic energy production were correlated with the behavioral responses to stimulation observed in these species. Among the terrestrial forms, Bufo, which were the slowest moving animals, showed no signs of exhaustion and had the lowest anaerobic scopes and capacities. In contrast, highly active animals such as Rana and Batrachoseps could sustain intense activity 
for only 1-2 min and tended to exhaust. Rana lost all locomotor activity by $5 \mathrm{~min}$. Batrachoseps initially responded by springing into the air and coiling and recoiling its body; it could still walk after 10-min stimulation but this characteristic escape response ceased after 1-2 min. These active species exhibited high rates of lactate production with high anaerobic capacities.

In aquatic species ('Table 2), lactate formation during normal activity (i.e. swimming with access to air) was considerably less than in terrestrial species. Both aquatic species, however, frequently gulped air during activity. If access to air was restricted, Notophthalmus underwent considerable anaerobic metabolism and became lethargic and uncoordinated after 4-5 min of swimming. Walking on land, these animals moved much more slowly than in water and utilized anaerobic metabolism more extensively than during swimming, in spite of freely available environmental oxygen. Rana catesbeiana tadpoles became lethargic during $10 \mathrm{~min}$ of activity in water; the lactate contents of these larvae $(0.67 \mathrm{mg} / \mathrm{g})$ were considerably less than those at which terrestrial species showed fatigue or became exhausted.

\section{DISCUSSION}

Anaerobic metabolism in amphibians is characterized by broad species diversity. These interspecific differences in anaerobic response are not strongly correlated with phylogenetic position; for example, differences between two anurans$R$. pipiens and $B$. boreas - are greater than between some urodeles and anurans. The differences in anaerobic pattern observed between the two closely related species of Aneides suggest that this response can show great interspecific variability among amphibians, even within the most limited taxonomic groups.

Anaerobic function in the amphibians investigated appears to be directly related to patterns of predator avoidance. Dr. S. Arnold (personal communication) has conducted experiments in which many of the animals investigated in this study were presented as prey to garter snakes (Thamnophis spp.). The amphibian responses of predator avoidance fall into two groups: one in which "frantic" activity is used to escape from the predator and the other in which animals rely instead on noxious skin secretions, postural adjustments or counterattack to avoid being eaten. The animals which engage in rapid flight (e.g. Batrachoseps, Rana, Hyla) all have high anaerobic scopes and capacities and show a marked diminution of activity level over time. 'The other group, including $B u f o, A$. lugubris and Notophthalmus, have low anaerobic scopes and capacities and can sustain activity almost indefinitely. The skin of Notophthalmus and Bufo has many poisonous secretions which deter some predators, although Thamnophis will attempt to eat $B u f o$; the toad then adopts an inflated posture to avoid being swallowed by the snake. A. lugubris, unlike its congener $A$. flavipunctatus, possesses relatively large sharp teeth and attacks and bites the predator, causing extensive bleeding and occasionally death (see also Brodie, 1973). These observations lead to the testable hypotheses that amphibians which rely on static defense mechanisms, for example, other poisonous newts and frogs will have low anaerobic scopes and be incapable of rapid activity. We may further hypothesize that rapid 
movement in amphibians is possible only at the cost of extensive anaerobic metabolism and that aerobiosis cannot be increased rapidly or extensively enough to support vigorous activity.

The aquatic species studied (Notophthalmus and $R$. catesbeiana tadpoles) are surprisingly reliant on aerobic metabolism and do not appear able to tolerate the disruptive effects of lactate production as well as terrestrial species. The increased dependence on anaerobic metabolism in Notophthalmus deprived of air may be important during courtship since the males of this species do not surface to gulp air (Arnold, 1972). The rapid exhaustion of newts deprived of air may explain why courtship is much slower and less vigorous than in aquatic urodele species which continue to gulp (e.g., Ambystoma maculatum) Anaerobic metabolism was also used when Notophthalmus were forced to move on land, during which time they had free access to oxygen. Apparently swimming is a much more efficient means of locomotion than walking in this species and its energetic demands can be sustained aerobically.

Previous observations support the correlations established here between anaerobiosis and activity pattern. Seymour (1973) reported that the toads Bufo cognatus and Scaphiopus hammondii show no fatigue during 20-min activity, experience a low degree of anaerobic metabolism (blood lactate: $56 \mathrm{mg} \%$ ) and have high aerobic scopes. $R$. catesbeiana and $R$. pipiens in contrast have low aerobic scopes and can sustain activity for only 2-3 min before exhaustion. Our measurements of $B$. boreas and $R$. pipiens agree with these observations. Leivestad (1960), however, reported high concentrations of blood lactate (mean: $74 \mathrm{mg} \%$; range: $33-122 \mathrm{mg} \%$ ) after only $30 \mathrm{sec}$ of hopping activity in Bufo viridis; thus, the possibility of major differences among congeneric species must be considered. The anaerobic scope $(0.65 \mathrm{mg} / \mathrm{g} \times \mathrm{min})$ and capacity $(0.74 \mathrm{mg} / \mathrm{g})$ of the caecilian Geotrypetes seraphinii are intermediate to the values reported here for both urodeles and anurans (Bennett \& Wake, 1974). Batrachoseps and Hyla were found to have low aerobic scopes and to obtain 93-98 per cent of their total energetic generation during a $30-\mathrm{sec}$ burst of activity from lactate production. In contrast, Bufo derives only 44 per cent of its energy during a similar activity period from anaerobiosis (Bennett \& Licht, 1973).

An aspect of anaerobiosis in amphibians which has been previously examined is tolerance to hypoxia or anoxia, since some of these animals are capable of sustained diving or overwintering under water. Amphibians exposed to acute anoxia (pure nitrogen) have an increased anaerobic metabolism and lactate production (Rose \& Drotman, 1967; Armentrout \& Rose, 1971; Rose et al., 1971). Amphibians, therefore, appear to have the capacity to respond to hypoxia with increased lactate production, but whether this capacity is utilized during normal diving is unclear. Diving in these animals is associated with a pronounced decrement in metabolic rate (Jones, 1971), such that cutaneous oxygen supply may be sufficient to support the reduced metabolic demands. Leivestad (1960) reported only a very modest rise in blood lactate $(+18 \mathrm{mg} \%$ ) after $2 \mathrm{hr}$ of diving in Bufo viridis, and Jones (1967) found no indication of anaerobiosis during diving in Rana temporaria. 
In general, ranids do have a longer survival time during diving than do bufonids (Czopek, 1962b; Hutchison \& Dady, 1964), a situation paralleled by their greater anaerobic scopes and capacities. Hutchison \& Dady (1964), however, attributed this differential survival to aerobic metabolic factors, such as a greater utilization of dissolved oxygen by Rana. Perhaps the application of our technique will prove useful in examinations of this problem in the future. At this point, activity appears to be a much more significant determinant of anaerobiosis in amphibians than hypoxia or anoxia.

The pronounced interspecific diversity in anaerobic capabilities and the relatively high thermal dependence of anaerobic metabolism in amphibians contrasts markedly with results obtained for lizards. Contrary to expectations, lactate production in amphibians appears to be more temperature dependent than in lizards. The thermal ranges examined in this study are not unreasonable for these species active in nature (Brattstrom, 1963), but only Rana at relatively high temperatures (above $20^{\circ} \mathrm{C}$ ) has the thermal independence of anaerobiosis $\left(Q_{10}=\right.$ $1 \cdot 1-1 \cdot 3)$ which is characteristic of several saurian species over their range of activity temperatures (Bennett $\&$ Licht, 1972). These $Q_{10}$ values for amphibians are generally similar to those reported for resting and active oxygen consumption for these and other amphibians $\left(Q_{10}=1 \cdot 3-2 \cdot 0\right)$ (Whitford \& Hutchison, 1967; Hutchison et al., 1968; Seymour, 1973).

Anaerobic capacities in the more anaerobic species of amphibians are similar to those observed in lizards (Fig. 3). However, lizards as a group appear to have a more highly developed anaerobic capability with regard to the initial rate of lactate production. Lizards representing several diverse families showed uniformly high anaerobic scopes. Among the amphibians, only Batrachoseps attained similar rates of lactate formation (Fig. 1). Most lizards are capable of only 2 min of maximal running activity and exhaust totally in $5 \mathrm{~min}$. Among the amphibians investigated, such exhaustion occurred only in $R$. pipiens, but the other anaerobic forms show similar tendencies during stimulation. Thus, the lizards and the most anaerobic amphibians may be approaching the physiological extreme of anaerobic activity since further intensification of anaerobic metabolism would result in such rapid exhaustion that it would have little survival value.

Acknowledgements-Support for this research was provided by a Miller Post-doctoral Research Fellowship to A. F. B. and NSF Grant GB-35241X to P. L. We wish to thank Dr. Steven Arnold, University of California, Santa Barbara, for permitting us to discuss his unpublished observations.

\section{REFERENCES}

Armentrout D. \& Rose F. L. (1971) Some physiological responses to anoxia in the Great Plains toad, Bufo cognatus. Comp. Biochem. Physiol. 39A, 447-455.

ARNOLD S. J. (1972) The evolution of courtship behavior in salamanders. Ph.D. thesis, University of Michigan, Ann Arbor.

Bennetr A. F. \& Dawson W. R. (1972) Aerobic and anaerobic metabolism during activity in the lizard Dipsosaurus dorsalis. F. comp. Physiol. 81, 289-299. 
Bennett A. F. \& Licht P. (1972) Anaerobic metabolism during activity in lizards. F. comp. Physiol. 81, 277-288.

BennetT A. F. \& Licht P. (1973) Relative contributions of anaerobic and aerobic energy production during activity in amphibia. $\%$. comp. Physiol. (In press.)

BENNETT A. F. \& WAKE M. (1974) Metabolic correlates of activity in the caecilian Geotrypetes seraphinii. Copeia. (In press.)

Brattstrom B. H. (1963) A preliminary review of the thermal requirements of amphibians. Ecology 44, 238-255.

Brodie E. D., Jr. (1973) Defensive mechanisms of plethodontid salamanders. Herpetol. Info. Search Sys. News-F. 1, 55.

Czopek J. (1962a) Vascularization of respiratory surfaces in some Caudata. Copeia 1962, $576-587$.

Czoper J. (1962b) Tolerance to submersion in water in amphibians. Acta biol. cracov. Ser. zool. 5, 241-251.

ELKan E. (1955) The buccal and pharyngeal mucous membranes in urodeles. Proc. Zool. Soc. Lond. 125, 685-710.

Hutchison V. H. \& Dady M. J. (1964) The viability of Rana pipiens and Bufo terrestris submerged at different temperatures. Herpetologica 20, 149-162.

Hutchison V. H., Whitford W. G. \& KоHL M. (1968) Relation of body size and surface area to gas exchange in anurans. Physiol. Zoöl. 41, 65-85.

JoNES D. R. (1967) Oxygen consumption and heart rate of several species of anuran amphibia during submergence. Comp. Biochem. Physiol. 20, 691-707.

JONES D. R. (1972) Anaerobiosis and the oxygen debt in an anuran amphibian, Rana esculenta (L.). F. comp. Physiol. 77, 356-382.

LEIVESTAD H. (1960) The effect of prolonged submersion on the metabolism and the heart rate in the toad (Bufo bufo). Arbok Univ. Bergen 5, 1-15.

Rose L. J. \& Drotman R. B. (1967) Anaerobiosis in a frog, Rana pipiens. F. exp. Zool. 166, $427-432$.

Rose F. L., Armentrout D. \& Roper P. (1971) Physiological responses of paedogenic Ambystoma tigrinum to acute anoxia. Herpetologica 27, 101-107.

Seymour R. S. (1973) Physiological correlates of forced activity and burrowing in the spadefoot toad, Scaphiopus hammondii. Copeia 1973, 103-115.

Whitford W. G. \& Hutchison V. H. (1965) Gas exchange in salamanders. Physiol. Zoöl. 38, 228-242.

Whitford W. G. \& Hutchison V. H. (1967) Body size and metabolic rate in salamanders. Physiol. Zoöl. 40, 127-133.

Key Word Index-Activity; amphibian; anaerobiosis; Batrachoseps; Bufo; frog; lactate; Rana; salamander; toad. 